\title{
Prevalence and clustering of cardiovascular disease risk factors in rural Nepalese population aged $40-80$ years
}

\author{
Mahesh Kumar Khanal 1,5* ${ }^{*}$, M. S. A. Mansur Ahmed², Mohammad Moniruzzaman², Palash Chandra Banik², \\ Raja Ram Dhungana ${ }^{1,6}$, Pratiksha Bhandari ${ }^{3}$, Surya Devkota ${ }^{4}$ and Arun Shayami ${ }^{4}$
}

\begin{abstract}
Background: Cardiovascular diseases (CVD) are the main cause of mortality in low- and middle-income countries like Nepal. Different risk factors usually cluster and interact multiplicatively to increase the risk of developing acute cardiovascular events; however, information related to clustering of CVD risk factors is scarce in Nepal. Therefore, we aimed to determine the prevalence of CVD risk factors with a focus on their clustering pattern in a rural Nepalese population.

Methods: A community-based cross-sectional study was conducted among residents aged 40 to 80 years in Lamjung District of Nepal in 2014. A clustered sampling technique was used in steps. At first, four out of 18 wards were chosen at random. Then, one person per household was selected randomly $(n=388)$. WHO STEPS questionnaires (version 2.2) were used to collect data. Chi-square and independent t-test were used to test significance at the level of $p<0.05$.

Results: A total 345 samples with complete data were analyzed. Smoking [24.1\% (95\% Cl: 19.5-28.6)], harmful use of alcohol [10.7\% (7.4-13.9)], insufficient intake of fruit and vegetable [72\% (67.1-76.6)], low physical activity [10.1\% (6.9-13.2)], overweight and obesity [59.4\% (54.2-64.5)], hypertension [42.9\% (37.6-48.1)], diabetes [16.2\% (14.0-18.3)], and dyslipidemia [56.0\% (53.0-58.7)] were common risk factors among the study population. Overall, $98.2 \%$ had at least one risk factor, while 2.0\% exhibited six risk factors. Overall, more than a half (63.4\%) of participants had at least three risk factors (male: 69.4\%, female: 58.5\%). Age [OR: 2.3 (95\% Cl: 1.13-4.72)] and caste/ethnicity [2.0 (95\% Cl: 1.28-3.43)] were significantly associated with clustering of at least three risk factors.

Conclusions: Cardiovascular risk factors and their clustering were common in the rural population of Nepal. Therefore, comprehensive interventions against all risk factors should be immediately planned and implemented to reduce the future burden of CVD in the rural population of Nepal.
\end{abstract}

Keywords: Cardiovascular diseases, Risk factors, Clustering of CVD risk factors, Smoking, Hypertension, Diabetes mellitus, Dyslipidemia, Rural population, Nepal

\section{Background}

Cardiovascular diseases (CVD) are the number one cause of mortality globally. In 2015, global estimated deaths caused by CVD were 17.7 million. More than three-quaters of these deaths occur in low- and middle-income countries [1]. In Nepal, the estimated age-standardized death rates caused by CVD (Ischemic

\footnotetext{
* Correspondence: drmkkhanal@gmail.com

${ }^{1}$ Bangladesh Institute of Health Sciences (BIHS), Dhaka, Bangladesh

${ }^{5}$ Ministry of Health and Population (MoHP), Kathmandu, Nepal

Full list of author information is available at the end of the article
}

Heart Disease and Cerebrovascular Diseases) were 152 and 82 per 100,000 population respectively in 2008 [2]. CVD were the second most common (40.0\%) noncommunicable diseases among indoor patients of the non-specialist hospitals of Nepal in 2010 [3]. Moreover, $13.8 \%$ of industrial workers of Nepal were diagnosed with CVD in 2016 [4].

Based on attributable deaths globally, common CVD risk factors are high blood pressure (to which $13.0 \%$ of global deaths is attributed), tobacco use $(9.0 \%)$, diabetes $(6.0 \%)$, physical inactivity (6.0\%), overweight/obesity (5.0\%),

(c) The Author(s). 2018 Open Access This article is distributed under the terms of the Creative Commons Attribution 4.0 International License (http://creativecommons.org/licenses/by/4.0/), which permits unrestricted use, distribution, and reproduction in any medium, provided you give appropriate credit to the original author(s) and the source, provide a link to the Creative Commons license, and indicate if changes were made. The Creative Commons Public Domain Dedication waiver (http://creativecommons.org/publicdomain/zero/1.0/) applies to the data made available in this article, unless otherwise stated. 
cholesterol (4.5\%), harmful use of alcohol (4.0\%), and low fruit and vegetable intake (3.0\%) $[2,5,6]$. In Nepal, hypertension was the most prevalent risk factor for CVD which ranged from $26.0 \%$ to $38.9 \%$ [7-11] during the last 3 years. Moreover, diabetes mellitus was seen in $8.4 \%$ of Nepalese population [12]. STEPS survey of Nepal in 2013 detected hypercholesterol in $23.0 \%$, smoking in $19.0 \%$, overweight in $21.0 \%$, raised blood glucose in $4.0 \%$, physical inactivity in $3.0 \%$, and harmful use of alcohol in 2.0\% [7]. These behavioral and metabolic risk factors usually cluster together, interact, and multiply so that the total risk of developing acute cardiovascular events is increased [13, 14]. In Asia, for instance, almost $44.0 \%$ of Chinese adult population had clustered at least two cardiovascular risk factors [15]. Moreover, in Nepal, more than $60.0 \%$ had a minimum of two clustered risk factors [7]. Evidence shows that about 58.0\% decline in CVD mortality has been attributed to reductions in the population levels of these risk factors [16, 17].

A recent study from China reported that low-income areas had a higher prevalence of total CVD compared to high-income areas [18]. In addition, cardiovascular health is poor in rural communities and disproportionally affects elderly populations [19]. Risk factors and their clustering phenomenon should be explored to plan and organize individual and population-based interventions in rural communities focusing on elderly population. However, there is no data available on status and clustering of all cardiovascular risk factors in the elderly rural population in Nepal. Therefore, we aimed to determine the prevalence of CVD risk factors with a focus on their clustering in rural Nepalese population aged $40-80$ years.

\section{Methods}

\section{Study design, settings, and participants}

The current article is a part of the study titled "Risk prediction of cardiovascular disease in selected rural communities of Nepal", details of the study are available elsewhere [20]. Briefly, the original study was a community-based cross-sectional study carried out in two rural villages (Bhotewodar and Sunderbazar) of Lamjung district (about $200 \mathrm{~km}$ west from capital city Kathmandu) of Nepal from October to November in 2014. The study area had 3869 households where 14,275 people were residing. Of these, about one-quater $(26.0 \%)$ were aged 40 to 80 years in the study area. Indigenous people like Gurung, Tamang, Magar, and Newar were major inhabitants in addition to Bramhan and Kshetri in the study site. Most of them were involved in agricultural work, livestock activities, grocery shops, and locally available jobs [21]. There were two sub-health posts and two fifteen-bed hospital in the communities. Any person who was residing for more than 6 months, aged 4080 years, and without a history of self-reported angina, myocardial infarction, stroke, intermittent claudication were included in the study. Those with an intelectual disability, bed-ridden patients, and pregnant women were excluded from the study.

\section{Sample size and sampling}

The estimated sample size was calculated based on the prevalence of current smoking (19.0\%) reported by nationwide study of Aryal et al. [7] at 5\% of allowable error. After adjusting for finite population correction and design effect (1.5), minimum required sample size was 331 . With an expectation of $15 \%$ non-response rate, the sample size was inflated to 390 . The study used a clustered sampling technique in three stages. The study considered the ward as the primary cluster which is the geographic and administrative unit of the communities. Culturally, economically, geographically, and socially diverse populations were residing in each ward, and these features were similar between wards [21]. The wards were selected based on per probability proportion to size (PPS). The sample size for each cluster was determined based upon their population size. In the first stage, out of 18 wards, four were selected. Secondly, systematic random sampling technique was used to select the required number of households from each ward. Every sixth household was considered for the study, starting from an arbitrary point. Finally, we used age and gender of the eligible participants of that household to place in selection grid of the Kish table so that we would interview only an eligible participant from each household [22].

\section{Data collection}

Data was collected by comprehensively trained health workers (two Auxiliary Nurse Midwifes, one Auxiliary Health Worker, and two third-year medical students) using standard WHO STEPS instrument version 2.2 [22]. We adopted all the core questionnaires as well as few of the extended questionnaires in our final tool. The tool was translated into Nepali by applying the forward and backward methodology and then pretested to 20 participants before the final implementation for piloting. Information on socio-demographic condition, behavioral risk factors, such as tobacco use, alcohol use, fruit and vegetable intake, physical activity, history of blood pressure, and diabetes were obtained by asking related questionnaires. For instance, we asked the question "do you currently smoke any tobacco products, such as cigarettes, cigars or pipes" to acquire information on current tobacco use. Alcohol consumption habit was ascertained asking "have you consumed an alcoholic drink within the past 30 days". If yes, we used show cards to estimate an average amount of standard drinks per day. Similarly, for assessing fruit and vegetable intake, we asked the question, "on how many days do you eat fruit and vegetable in a typical week". If they responded one or more days, we displayed show cards to calculate average 
numbers of fruit and vegetable servings per day. Height, weight, waist circumference, and blood pressure were measured precisely using standard methods as described in WHO STEPs manual [22]. Height and weight were measured over a light cloth and without foot bearings using the portable weighing machine and stadiometer, respectively. The non-elastic measuring tape was used to measure waist circumference at the level of the umbilicus (midway between last rib and anterior superior iliac spine) during normal respiration. Doctor's aneroid sphygmomanometer with an appropriate sized cuff and a stethoscope were utilized over the unclothed left arm to measure blood pressure. Three blood pressure readings were obtained, the first after at least $15 \mathrm{~min}$, second and third after at least five-minute intervals. Finally, the participants were invited in the next morning, after overnight fasting, to a nearby hospital or community centre, where, skilled phlebotomist withdrew venous blood to measure fasting blood sugar and lipid profile. Participants without known diabetes were then requested to drink $75 \mathrm{~g}$ of anhydrous glucose mixed with $250 \mathrm{ml}$ of water within five minutes. Another one milliliter of venous blood was also collected two hours after the oral glucose intake for oral glucose tolerance test. Blood sugar and lipid profile were measured using a semi-automated machine of Erba Mannheim (Germany), chem. 5 v3 model in the laboratory of a nearby community hospital.

\section{Definition of variables}

\section{Demographic and socio-economic variables}

Age was taken in complete years. Education was categorized into illiterate and no formal education (< grade 1), primary (grade $1-5$ ) and more than or equal to secondary ( $\geq$ grade 6 ). Caste was divided into upper caste (Bramhan and Kshetri), Janajati (Gurung, Tamang, Newar, Magar, and Thakali) and Dalit (low caste). Information related to occupation was subdivided into employed, self-employed (operating own business), unemployed (student or house-maker or non-paid workers), and retired. Poor was defined as any participant whose family income per person per year was less than 18,428 rupees (\$184.2) [23].

\section{Variables related to behavior (STEP I)}

Current smoking was defined as those who were smoking cigarettes and those who quit less than 1 month before data collection. Similarly, those who were chewing tobacco in the last 30 days were defined as current smokeless tobacco users [22]. The total amount of alcohol intake was calculated in a number of the standard drink ( $10 \mathrm{~g}$ of pure ethanol). Average consumption of alcohol of at least one (women) or two (men) standard drinks per day over last 30 days was defined as the harmful use of alcohol [24]. Insufficient intake of fruit and vegetable was considered if the participants consumed less than five servings (400 g) per day [22]. Physical activities were measured in metabolic equivalents of task (METs) minutes per week. Low level physical activities (physically inactive) was defined as less than 600 MET-minutes per week of physical activities [22].

\section{Anthropometric measurements (STEP II)}

Weight was divided by square of height (in meters) to calculate Body Mass Index (BMI) of participants. The BMI was classified as underweight $\left(<18.5 \mathrm{Kg} / \mathrm{m}^{2}\right)$, normal $\left(18.5-24.9 \mathrm{Kg} / \mathrm{m}^{2}\right)$, overweight $\left(\geq 25-29.9 \mathrm{Kg} / \mathrm{m}^{2}\right)$, and obese $\left(\geq 30 \mathrm{Kg} / \mathrm{m}^{2}\right)$ [25]. Raised waist circumference (central obesity) was defined as the raised level if it was more than $88 \mathrm{~cm}$ in women and more than $102 \mathrm{~cm}$ in men [26]. For blood pressure, an average of the last two readings was used in the final analysis. Hypertension was defined as average systolic blood pressure $(\mathrm{SBP}) \geq 140 \mathrm{mmHg}$ and/or average diastolic blood pressure (DBP) $\geq 90 \mathrm{mmHg}$ and/or history of taking antihypertensive medication in the last 2 weeks [27].

\section{Biochemical variables (STEP III)}

Diabetes mellitus was defined by the presence of fasting blood sugar $\geq 126 \mathrm{mg} / \mathrm{dl}$ (milligram/deciliter) and/or post prandial blood sugar $\geq 200 \mathrm{mg} / \mathrm{dl}$ and/or intake of any anti-diabetic drugs [28]. Dyslipidemia was defined as presence of at least one of the following; raised total cholesterol $(>200 \mathrm{mg} / \mathrm{dl})$, raised triglyceride $(>150 \mathrm{mg} / \mathrm{dl})$, raised low-density lipoprotein $(>130 \mathrm{mg} / \mathrm{dl})$, decreased high-density lipoprotein $(<40 \mathrm{mg} / \mathrm{dl}$ in male and $<50 \mathrm{mg} /$ $\mathrm{dl}$ in female), and/or use of antilipidemic drug [29].

\section{Clustering of risk factors}

The clustering of modifiable CVD risk factors were assessed based on the presence of eight major risk factors; current smoking, harmful use of alcohol, low fruit and vegetable intake, low physical activity, overweight or obesity, hypertension, diabetes, and dyslipidemia.

\section{Statistical analysis}

Data was compiled and edited to maintain consistency before entering into Epidata version 3.1. Duplications were removed and exported into SPSS V.16.0 for further analysis. Simple descriptive statistics were used for socio-demographic characteristics. Prevalence of risk factors was computed in percentage with $95 \%$ confidence interval (CI). In the next step, age and sex adjusted prevalence of CVD risk factors was computed using WHO world standard population distribution between 2000 and 2025 considering sex weight of 0.5 [30]. Clustering of risk factors was presented as a percentage. Mean and standard deviations (SD) were reported for normally distributed continuous variables. Median with interquartile range was reported for non-normally distributed continuous variable. 
Correlation between different risk factors was determined using Pearson's correlation coefficients. Socio-demographic variables were entered into simple and multiple logistic regression models to determine crude and adjusted odds ratios, respectively. Chi-square and independent t-tests were used to compare categorical and continuous variables, respectively. Mann-Whitney $U$ test was used to test for non-normally distributed variables. All tests were two tail test and $p<0.05$ was considered statistically significant.

\section{Ethical consideration}

Ethical Review Board of Nepal Health Research Council reviewed and approved the study protocol. Before data collection, data enumerator informed all the eligible participants about the study objectives, data collection procedures, benefits and risks of the study, confidentiality, and anticipated use of the results. Then, the enumerators (health professionals) obtained written consent or thumb impression (if unable to write) using a consent form in Nepali language.

\section{Results}

\section{Socio-demographic characteristics}

Overall, 345 samples with complete data were analysed excluding 43 participants who did not participate in biochemical assessment. Socio-demographic characteristics of the study subjects are presented elsewhere [20]. In brief, more than half of the participants were females (55.4\%), aged $53.5 \pm 10.1$ years, and $40 \%$ of them were aged $40-49$ years. About half of the participants (53.6\%) were uneducated and from Janajati (55.5\%) population. The majority were unemployed (58.0\%). Almost all participants were married (91.3\%) and poor (97.1\%). Out of participants who did not attend the biochemical assessment, mean age was $52 \pm 10.7$ years, $55.8 \%$ were female, $55.8 \%$ did not have formal education, $51.2 \%$ were Janajati, $67.4 \%$ were unemployed. These characteristics were not significantly different from the participants who had completed the study.

\section{Prevalence of cardiovascular disease risk factors}

On average, participants were smoking at least two cigarettes per day. Additionally, participants were consuming at least one standard drink per day. Overall, the median intake of fruit and vegetable was four servings per day, and median physical activity was 3360 METs-minutes per week. Mean body mass index was $25.9( \pm 4.2) \mathrm{Kg} / \mathrm{m}^{2}$ and mean waist circumference was $88.8( \pm 11.7) \mathrm{cm}$. The average systolic and diastolic blood pressure were $124.5( \pm 18.7) \mathrm{mm}$ $\mathrm{Hg}$ and $88.8( \pm 10.8) \mathrm{mm} \mathrm{Hg}$, respectively. The mean fasting blood sugar, total cholesterol, triglyceride, high-density lipoprotein, and low-density lipoprotein were $92.8( \pm 34.1)$ $\mathrm{mg} / \mathrm{dl}, 165.1( \pm 34.9) \mathrm{mg} / \mathrm{dl}, 129.9( \pm 69.2) \mathrm{mg} / \mathrm{dl}, 53.2$
$( \pm 12.5) \mathrm{mg} / \mathrm{dl}$, and $86.3( \pm 33.6) \mathrm{mg} / \mathrm{dl}$, respectively. Standard drinks of alcohol per day $(p=<0.001)$, waist circumference $(p=<0.001)$, diastolic blood pressure $(p=0.008)$, total cholesterol $(p=0.009)$, and triglyceride $(p=0.009)$ were significantly different between men and women (Table 1).

The overall prevalence of current smoking was $24.1 \%$ (95\% CI: 19.5-28.6) with a higher proportion in men (29.2\%) compared to women (20.0\%). About one-fifth (19.0\%) were using smokeless tobacco (men: 29.6\%, women: $11.0 \%)$. Overall, $10.7 \%$ (95\% CI: 7.4-13.9) were drinking a harmful dose of alcohol (men: 21.4\%, women: $2.3 \%$ ). Similarly, $10.1 \%$ (95\% CI: $6.9-13.2$ ) were physically inactive. Women were less physically active $(12.6 \%)$ compared to men (7.1\%). Additionally, $72.0 \%$ (95\% CI: 67.1-76.6) were consuming less than five servings of fruit and vegetable daily (men: $76.6 \%$, women: $68.0 \%$ ) (Table 2 ).

Overweight and obesity was observed among 59.4\% (95\% CI: 54.2-64.5) of participants while 31.3\% (95\% CI: 26.4-36.1) of participants had central obesity. Overweight and obesity was higher in males $(61.0 \%)$ than in females (58\%), whereas central obesity was higher in women $(55.0 \%)$ compared to men (14.3\%). The overall prevalence of hypertension was $42.9 \% \quad(95 \%$ CI: 37.6-48.1) where more men (46.8\%) compared to women (39.8\%) had raised blood pressure (Table 2).

Diabetes mellitus was determined in $16.2 \%$ (95\% CI: 14.0-18.3) of total study subjects. Out of all, dyslipidemia was revealed in $56.0 \%$ (95\% CI: $53.0-58.7$ ) of participants. Dyslipidemia was higher in women (59.7\%) compared to men (52.0\%). When analysed separately, 29.9\% (95\% CI: 27.2-32.5) had raised high-density lipoprotein, $27.2 \%$ (95\% CI: $24.6-29.7$ ) had elevated triglyceride, $17.1 \%$ (95\% CI: 14.9-19.2) had increased level of total cholesterol and 10.4\% (95\% CI: 8.6-12.1) had raised low-density lipoprotein (Table 2).

\section{Distribution of cardiovascular disease risk factors}

The proportion of current smoking $(p=0.04)$, harmful use of alcohol $(p<0.001)$, raised waist circumference $(p=0.001)$, raised triglycerides $(p=0.007)$, and decreased high-density lipoprotein $(p=0.001)$ were significantly different between men and women (Table 2).

The proportion of current smoking, less fruit and vegetable intake, hypertension, and diabetes increased with increased age. In opposition, the proportion of harmful use of alcohol, physical inactivity, overweight/ obesity, and dyslipidemia decreased with increased age. However, only overweight and obesity were significantly associated with age $(p=0.002)$ (Table 2).

The harmful use of alcohol was significantly associated with the level of education $(p=0.003)$, caste $(p=0.02)$, and economic status $(p=0.046)$. It was highest among 
Table 1 Distribution of cardiovascular disease risk factors of study subjects by gender

\begin{tabular}{|c|c|c|c|c|}
\hline \multirow[t]{2}{*}{ Risk factors } & \multirow{2}{*}{$\begin{array}{l}\text { Both sexes } \\
\text { Mean (SD) }\end{array}$} & \multirow{2}{*}{$\begin{array}{l}\text { Men } \\
\text { Mean (SD) }\end{array}$} & \multirow{2}{*}{$\begin{array}{l}\text { Women } \\
\text { Mean (SD) }\end{array}$} & \multirow[t]{2}{*}{$P$ value } \\
\hline & & & & \\
\hline Average cigar per day & $1.98(5.2)$ & $2.2(5.7)$ & $1.8(4.7)$ & 0.478 \\
\hline Standard drinks of alcohol/day & $0.8(2.5)$ & $1.6(3.5)$ & $0.09(0.64)$ & $<0.001$ \\
\hline Fruit/vegetable (servings/day) $)^{a}$ & $4.0(2.0)$ & $4(1.0)$ & $4(2.0)$ & 0.101 \\
\hline Metabolic equivalent - minute/week ${ }^{a}$ & $3360.0(3576.0)$ & $3150.0(3600.0)$ & $3600.0(3525.0)$ & 0.121 \\
\hline Body Mass Index $\left(\mathrm{Kg} / \mathrm{m}^{2}\right)$ & $25.9(4.2)$ & $25.9(3.4)$ & $25.9(4.6)$ & 0.996 \\
\hline Waist circumference (cm) & $88.8(11.7)$ & $91.9(9.9)$ & $86.3(12.3)$ & $<0.001$ \\
\hline Systolic Blood Pressure (mmHg) & $124.5(18.7)$ & $126.8(18.7)$ & $122.6(18.4)$ & 0.039 \\
\hline Diastolic Blood pressure (mmHg) & $79.9(10.8)$ & $81.6(11.6)$ & $78.5(9.9)$ & 0.008 \\
\hline Fasting Blood Sugar (mg/dl) & $92.8(34.1)$ & $91.7(23.8)$ & $93.6(40.5)$ & 0.61 \\
\hline Total cholesterol (mg/dl) & $165.1(34.9)$ & $170.6(34.4)$ & $160.7(34.8)$ & 0.009 \\
\hline Triglyceride (mg/dl) & $129.9(69.2)$ & $138.7(76.6)$ & $119.2(61.4)$ & 0.009 \\
\hline High-density Lipoprotein (mg/dl) & $53.2(12.5)$ & $53(12.3)$ & $53.3(12.7)$ & 0.8 \\
\hline Low-density Lipoprotein (mg/dl) & $86.3(33.6)$ & $89.8(33.5)$ & $83.4(33.5)$ & 0.03 \\
\hline
\end{tabular}

${ }^{a}$ median Interquartile range, SD Standard Deviation

participants who had at least secondary level of education (11.0\%) and who were Dalit (28.6\%) (Table 3).

Overweight and obesity was associated with ethnicity $(p=0.007)$ with the highest prevalence among Dalit $(66.7 \%)$ participants. Waist circumference was associated with the level of education $(p=0.001)$ and occupation $(p<0.001)$. It was highest among uneducated (39.5\%) and unemployed (38.5\%). Hypertension was associated with occupation $(p=0.071)$, and retired participants had highest prevalence (59.3\%) (Table 3).

Prevalence of diabetes mellitus was significantly different among different levels of education $(\mathrm{p}=0.02)$. It was highest among those with at least secondary level education $(24.4 \%)$. Raised total cholesterol $(p=0.03)$ was significantly different among different ethnic groups. Similarly, the raised triglyceride was associated with the level of education $(p=0.01)$. High-density lipoprotein was associated with the level of education $(p=0.002)$ and the occupation $(p=0.006)$ (Table 3$)$.

\section{Correlation between cardiovascular disease risk factors}

Correlations between different risk factors were weak. Stronger correlations were observed between smoking and alcohol intake, diastolic blood pressure and body mass index along with waist circumference and triglyceride (Table 4).

\section{Clustering of cardiovascular disease risk factors}

Almost all of the participants (98.2\%) had at least one risk factor. In addition, $86 \%$ of total participants had clustering of at least two risk factors. Overall, $63.4 \%$ of participants had at least three risk factors (male: 69.4\%, female: 58.5\%). Clustering of at least four risk factors was observed among aproximately one-third of the participants (30.4\%). Clustering was higher among males (36.3\%) compared to females (25.6\%) (Fig. 1). About $2.0 \%$ (male: $3.2 \%$, female: $1 \%$ ) had up to six risk factors. We studied the socio-economic determinants of clustering of at least three risk factors, as after this clustering was suddenly dropped down. In univariate logistic regression; gender, age, and caste/ethnicity were significantly associated with clustering of at least three risk factors. However, after adjusting for all other socio-demographic factors, age and caste/ethnicity were significantly associated with clustering of risk factors (at least three). Odds of clustering of at least three risk factors was 2.3 times (95\% CI: $1.13-4.72)$ in the age group of 60-69 years compared to 40-49 years of age. Dalits had two times (95\% CI: 1.28-3.43) more chance of risk factor clustering compared to upper caste residents (Table 5).

\section{Discussion}

This study determined the prevalence of cardiovascular disease risk factors along with their clustering phenomenon in a rural population of Nepal. Prevalence of each cardiovascular risk factor was high and a maximum of six risk factors was clustered in some study participants.

Our current study revealed that approximately one-quater $(24.1 \%)$ were smoking cigarettes in a rural population of Nepal. Our finding was consistent with the tobacco smoking prevalence reported in other studies in Nepal. For instance, the proportion of current smoker was $29.0 \%$ in STEPS survey 2013 of Nepal among aged 4069 years [7] and 28.6\% in rural Sindhuli [31]. However, the prevalence of smoking found in our study was higher compared to that found in the capital city Kathmandu in 


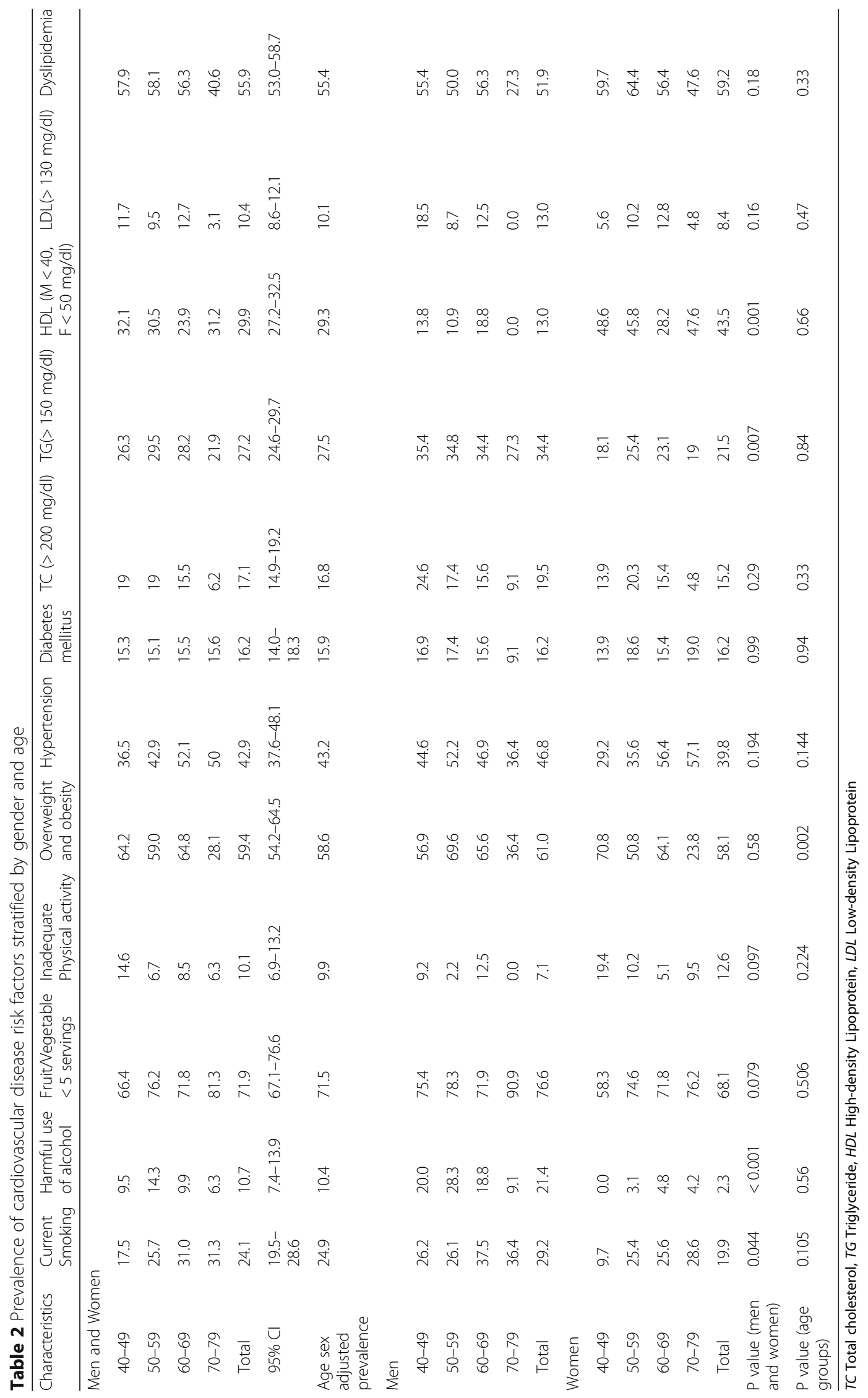




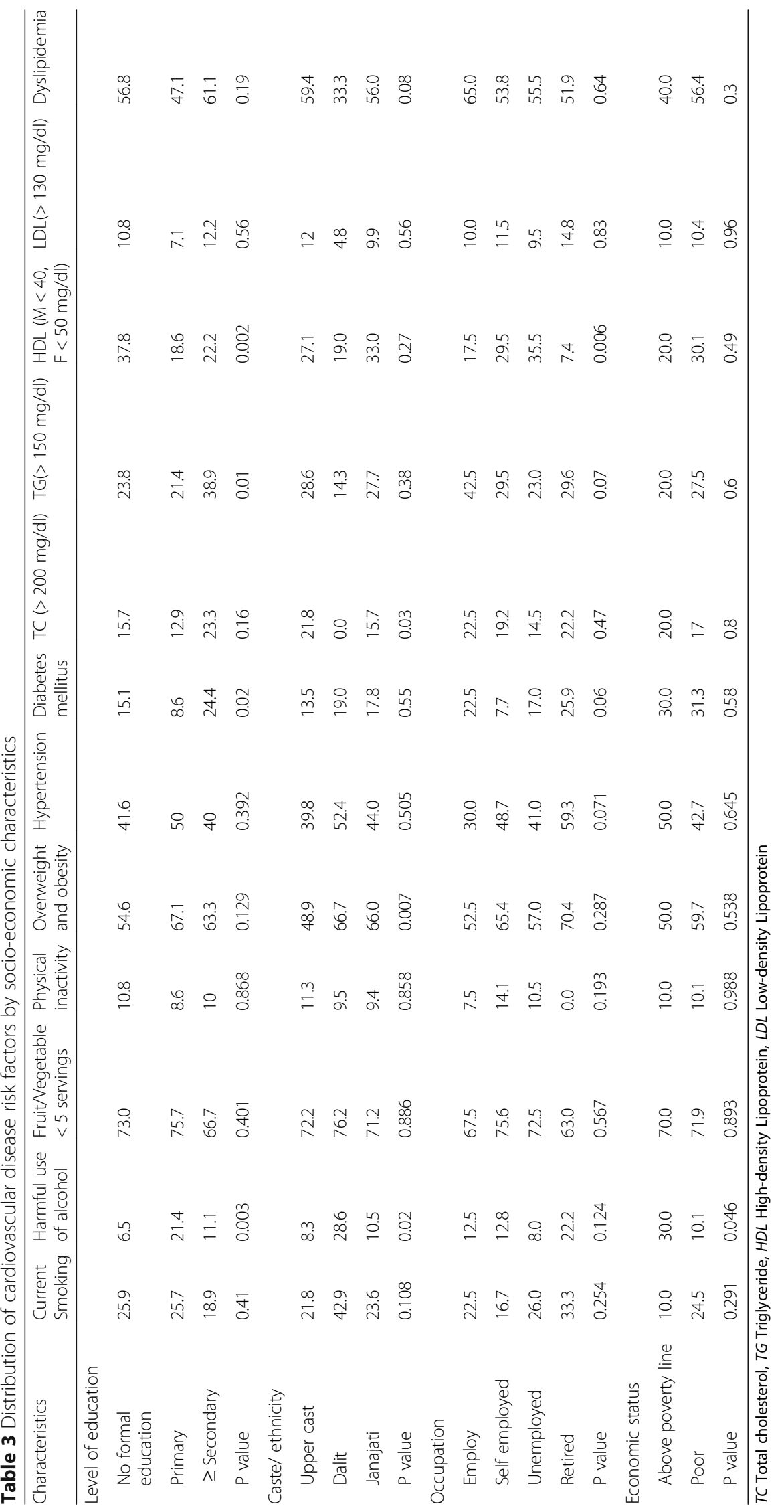


Table 4 Correlation between different cardiovascular disease risk factors

\begin{tabular}{|c|c|c|c|c|c|c|c|c|c|c|c|c|c|}
\hline & CG & $\mathrm{AL}$ & FV & MET & $\mathrm{BMI}$ & WC & SBP & DBP & FBS & $\mathrm{TC}$ & $\mathrm{TG}$ & $\mathrm{HDL}$ & $\mathrm{LDL}$ \\
\hline \multicolumn{14}{|l|}{$\overline{C G}$} \\
\hline $\mathrm{AL}$ & $.286^{\mathrm{a}}$ & & & & & & & & & & & & \\
\hline FV & -.045 & -.087 & & & & & & & & & & & \\
\hline MET & .018 & .023 & .016 & & & & & & & & & & \\
\hline $\mathrm{BMI}$ & -.096 & -.049 & .077 & -.029 & & & & & & & & & \\
\hline WC & $-.121^{b}$ & -.007 & .055 & -.090 & $.569^{\mathrm{a}}$ & & & & & & & & \\
\hline SBP & -.010 & $.117^{\mathrm{b}}$ & -.025 & .028 & $.118^{\mathrm{b}}$ & $.162^{\mathrm{a}}$ & & & & & & & \\
\hline DBP & -.078 & .065 & -.050 & -.065 & $.201^{a}$ & $.219^{a}$ & $.769^{\mathrm{a}}$ & & & & & & \\
\hline FBS & -.013 & .011 & -.037 & -.075 & .022 & .032 & .018 & .037 & & & & & \\
\hline $\mathrm{TC}$ & .010 & .100 & .037 & -.022 & -.035 & .001 & .033 & .030 & .098 & & & & \\
\hline $\mathrm{TG}$ & -.038 & -.026 & -.012 & -.048 & .096 & $.181^{\mathrm{a}}$ & $.133^{\mathrm{b}}$ & $.125^{b}$ & $.198^{\mathrm{a}}$ & $.250^{\mathrm{a}}$ & & & \\
\hline $\mathrm{HDL}$ & .078 & $.173^{\mathrm{a}}$ & .040 & .012 & -.034 & -.101 & -.005 & -.098 & $.136^{\mathrm{b}}$ & $.195^{\mathrm{a}}$ & -.075 & & \\
\hline $\mathrm{LDL}$ & -.004 & .050 & .029 & -.008 & -.064 & -.036 & -.019 & .016 & -.030 & $.863^{\mathrm{a}}$ & $-.123^{b}$ & $-.140^{a}$ & \\
\hline
\end{tabular}

CG Average no. of cigarettes/day, AL Average standard drinks/day, FV Total servings of fruit and vegetable/day, METs Total METs-Minutes/week, BMI Body Mass Index, WC Waist circumference, SBP Systolic Blood Pressure, DBP Diastolic Blood pressure, FBS Fasting Blood Sugar, TC Total cholesterol, TG Triglyceride, HDL Highdensity Lipoprotein, LDL Low-density Lipoprotein

${ }^{a}$ Correlation is significant at the 0.01 level

${ }^{\mathrm{b}}$ Correlation is significant at the 0.05 level

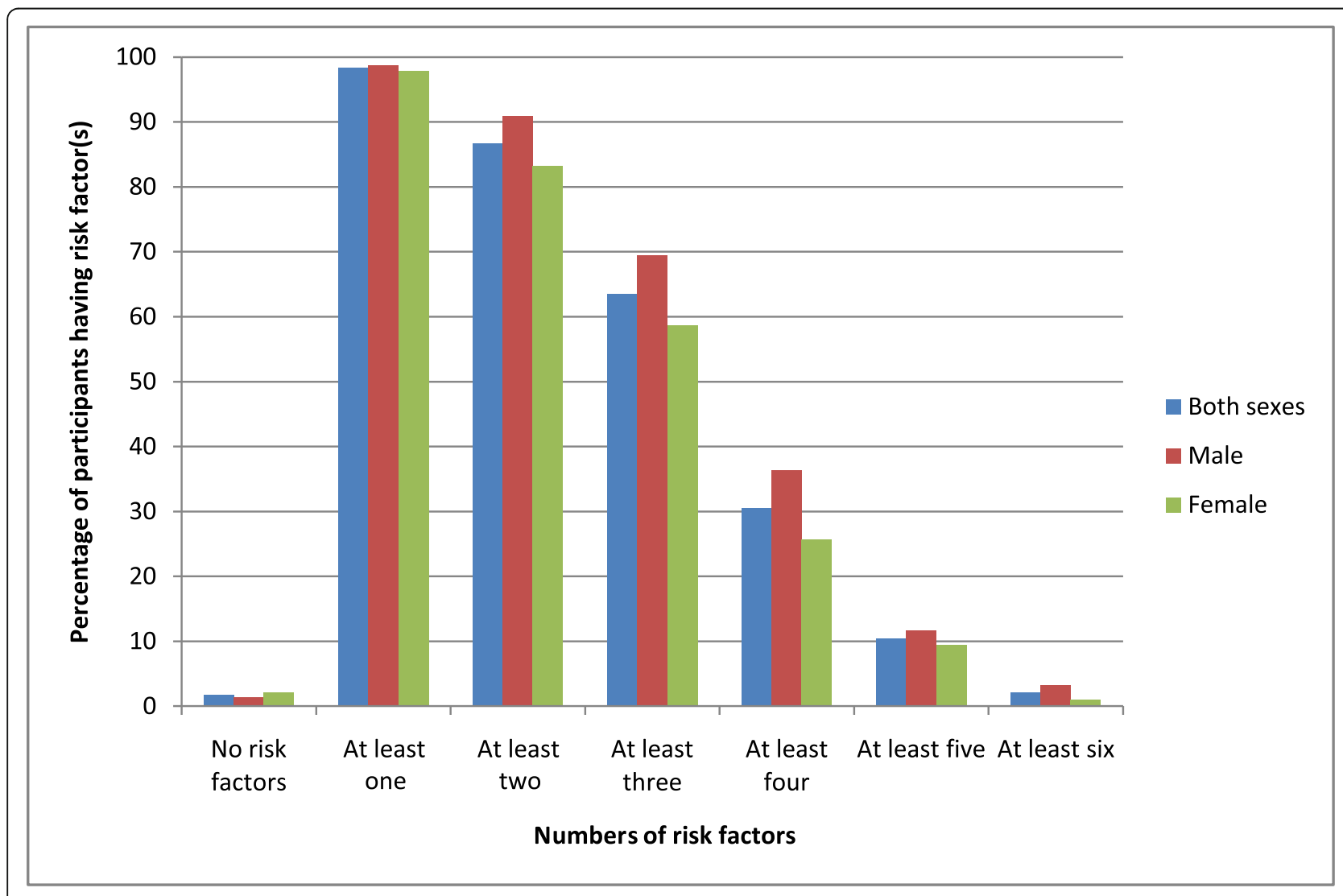

Fig. 1 Distribution of clustering of cardiovascular disease risk factors by gender 
Table 5 Socio-demographic factors associated with clustering of cardiovascular risk factors three or more

\begin{tabular}{|c|c|c|}
\hline Characteristics & Crude odds ratio $(95 \% \mathrm{Cl})$ & Adjusted odds ratio $(95 \% \mathrm{Cl})$ \\
\hline \multicolumn{3}{|l|}{ Sex } \\
\hline Female & $\operatorname{Ref}^{a}$ & Ref \\
\hline Male & $1.60(1.02-2.51)$ & $1.53(0.80-2.93)$ \\
\hline \multicolumn{3}{|l|}{ Age } \\
\hline $40-49$ & Ref & Ref \\
\hline $50-59$ & $1.27(0.75-2.14)$ & $1.39(0.79-2.45)$ \\
\hline $60-69$ & $1.89(1.01-3.53)^{a}$ & $2.31(1.13-4.72)^{a}$ \\
\hline $70-79$ & $0.88(0.40-1.83)$ & $0.94(0.38-2.31)$ \\
\hline \multicolumn{3}{|l|}{ Level of Education } \\
\hline No formal education & Ref & Ref \\
\hline Primary & $0.78(0.46-1.33)$ & $0.80(0.36-1.77)$ \\
\hline$\geq$ Secondary & $0.95(0.49-1.85)$ & $0.87(0.42-1.81)$ \\
\hline \multicolumn{3}{|l|}{ Caste/Ethnicity } \\
\hline Upper cast & $\operatorname{Ref}^{a}$ & $\operatorname{Ref}^{a}$ \\
\hline Janajati & $0.55(0.35-0.88)^{a}$ & $2.03(0.71-5.82)$ \\
\hline Dalit & $1.14(0.42-3.09)$ & $2.09(1.28-3.43)^{a}$ \\
\hline \multicolumn{3}{|l|}{ Marital Status } \\
\hline Married & Ref & Ref \\
\hline Widow or Widower & $0.85(0.38-1.89)$ & $0.71(0.29-1.74)$ \\
\hline \multicolumn{3}{|l|}{ Occupation } \\
\hline Employ & Ref & Ref \\
\hline Self employed & $1.34(0.60-3.00)$ & $1.09(0.46-2.62)$ \\
\hline Unemployed & $0.93(0.46-1.89)$ & $0.80(0.32-2.02)$ \\
\hline Retired & $1.19(0.43-3.34)$ & $0.70(0.22-2.16)$ \\
\hline \multicolumn{3}{|l|}{ Economic status } \\
\hline Higher(> NRs 8498) & Ref & Ref \\
\hline Poor ( $\leq$ NRs 8498) & $1.16(0.32-4.20)$ & $1.22(0.31-4.75)$ \\
\hline
\end{tabular}

${ }^{\mathrm{a}}$ significant at the 0.05 level

urban settings (20.0\%) [10] and rural settings (21.7\%) $[10,32]$ and the sub-metropolitan city Pokhara (17.0\%) [8] of Nepal. In all of these studies, more males compared to females were smoking cigarettes. These studies revealed the severity of smoking in Nepal.

One in ten study participants was drinking a harmful dose of alcohol in the current study. Similar result was observed in a recent study conducted in Pokhara (12.0\%) of Nepal [8]. However, our finding was higher than the report of STEPs survey of 2013 (2.7\%) for the 45 to 69 years of age group [7]. Most of the current study subjects were of indigenous and Dalit caste. Such ethnic people were more likely to drink alcohol and brew alcohol at home [33], which might be the reason for higher prevalence.

The burden of low fruit and vegetable intake was high in Nepal. The current study determined that about two-thirds $(72.0 \%)$ were not consuming five servings of fruit and vegetable per day. This prevalence was lower when compared with the result of a study representing the whole country (99.0\%) [7] and a study from surveillance site in Bhaktapur (97.9\%) of Nepal [34]. Variation according to age, race/ethnicity, income, education, and availability of fruit and vegetable are established socio-demographic factors for low fruit and vegetable intake $[35,36]$.

Ten percent of our study participants were engaged in a low level of physical activities. This prevalence was in line with the findings from Pokhara of Nepal (7.0\%) and world health survey for physical activities $(8.0 \%)[8,37]$. However, current prevalence was less than the findings of capital city Kathmandu (40.2\%) [10], Eastern region (37.6\%) [38], and Bhaktapur (male: $18.0 \%$ and female: 22.0\%) of Nepal [39]. Work and travel related activities are the major domains for physical activities in Nepal [39]. These domains are more pronounced in rural areas, and might be the reason for the lower prevalence of physical inactivity in our study. 
About six in ten participants (59.0\%) were overweight and obese in our study population. This prevalence was comparable with the result of Western Nepal (60.7\%) [38]. However, it was three-times greater than the findings of a stepwise survey of risk factors in Nepal (21.0\%) [7]. The higher prevalence of overweight and obesity may be related to the higher proportion of participants who smoke cigarette, chew tobacco, drink alcohol, and indulge in less physical activities in the current study population. Evidences support that alcohol energy intake may be responsible for weight gain if not counterbalanced, for instance, by physical activities [40]. However, further studies would be needed to confirm and explain our findings.

Two-fifths of participants $(43.0 \%)$ had hypertension in our study. The prevalence of hypertension in the current study (38.9\%) was comparable with above-mentioned STEPS survey $(47.0 \%)$ for the respective age of more than 45 years [7]. However, hypertension was greater in our study compared to populations from Eastern Nepal (34.0\%) [38], municipalities of Kathmandu (32.5\%) [10], Pokhara-Lekhnath (28.0\%) [8], Dhulikhel (27.7\%) [9], and Surkhet (38.9\%) [11] of Nepal. Alcohol consumption, body mass index, total cholesterol, and triglyceride were correlated to systolic and diastolic blood pressure in our study. The high prevalence of these risk factors in our study might explain the higher rates of hypertension.

The prevalence of diabetes mellitus was $16.2 \%$ in our study. This prevalence was higher than the reported prevalences from Eastern Nepal for the age group 40 to 80 years (11.5\%) [38], STEPS survey 2013 (9.0\%) for age group 4569 years [7], and rural population of Sunsari (9.0\%) [41]. One study conducted in Kathmandu valley reported that $25.9 \%$ of participants aged 60 years and older had diabetes mellitus [42]. That means elderly age group has the higher chance of diabetes [43]. A high proportion of diabetes in our study could be a result of the high prevalence of triglyceride that was correlated with fasting blood sugar. Another reason for a higher burden of diabetes in our study may be because of the use of an oral glucose tolerance test for those who did not have known diabetes.

Our study revealed more than half $(56.0 \%)$ of participants of the rural population had dyslipidemia. This overall dyslipidemia was accounted by $17.0 \%$ of elevated total cholesterol, $27.0 \%$ of raised triglyceride, $30.0 \%$ decreased high-density lipoprotein, and $10.0 \%$ of raised low-density lipoprotein among all the study subjects. When compared with above-mentioned STEPS survey, our study population had less prevalence of dyslipidemia. For instance, among participants of age group 45 to 69 years of age, 33\% had raised cholesterol, 35\% had elevated triglyceride, and $24 \%$ had elevated low-density lipoprotein in the STEPS survey [44]. Furthermore, the proportion of dyslipidemia in our study was less compared to another study from non-diabetes participants of the urban area of the capital city Kathmandu, which determined $73.3 \%$ had dyslipidemia [45]. Our study revealed that prevalent risk factors namely waist circumference, systolic blood pressure, and fasting blood sugar were correlated with triglyceride level. Similarly, alcohol intake and fasting blood sugar were positively correlated with the reduction of serum high-density lipoprotein. All of these may have been responsible for such high prevalence of dyslipidemia.

Almost all of the study population had at least one risk factor. The finding of our study was consistent with the STEPS survey 2013 of Nepal which revealed $99.6 \%$ of participants had at least one risk factor [7]. When compared with the studies from other Asian countries, clustering of at least two risk factors was observed in $44 \%$ of Chinese population [15] and 76\% of cases in Bangladesh [46]. Comparably, the current study displayed $86 \%$ of study participants had a minimum of two risk factors clustered together. The current finding of clustering of three to five risk factors (63.4\%) was higher compared to STEPS survey 2013 (30.0\%) for the age group 45 to 69 years [7]. Our study included the harmful use of alcohol, diabetes, and dyslipidemia when analyzing the clustering phenomenon, which the STEPS survey did not. This could explain the disparity between the findings.

When different risk factors act together, the effect will be multiplicative and raises the risk of CVD more than the summation of risk factors [13, 14]. For instance, one study reported that incidence of ischemic heart disease rises from 0 to $40 \%$ as the number of risk factors conglomerate from zero to five among diabetic patients [47]. Moreover, annual medical expenditure increases with the rise in clustering of risk factors [48]. In our study greatest clustering was observed among 60-69 years of age group and Dalit participant. Therefore, it could be pronounced that preventive strategies should be focused on individuals who have more risk factors and especially elderly population who are aged 60-69 years and are Dalit.

It is important to emphasize health education programs that warn about the behavioral risk factors of CVD. In addition, early detection and treatment of intermediary risk factors (hypertension, diabetes, dyslipidemia and overweight) are required to minimize the future burden of CVD [2]. Health promotion approaches could be delivered through various approaches: health workforce, trained community volunteers of the current health system, school health programs or media campaigns [49-51] collaborating with all stakeholders. Such community-based programs have already been implemented in developed and developing countries [50, 52]. Package of Essential Noncommunicable Disease (PEN) interventions could be implemented to prevent cardiovascular diseases as well, so that the community could utilize current health care delivery system [53]. One study from Northern India revealed that the primary 
health care setting was a feasible setting for CVD risk management even in rural areas [52].

Our study had several limitations. The study was conducted in a selected rural community where a large population of Janajati and women were residing. Our sample size was not large enough to make it a representative sample of all the risk factors. As we have included participants aged 40 to 80 years, we could not report the status of risk factor among the younger population. The current study might have underestimated the cardiovascular risk factors, as it excluded those who had known heart diseases, stroke, or intermittent claudication. The prevalence of risk factors might have been underestimated as about $11.0 \%$ of total participants did not involve in biochemical assessment, though socio-demographic characteristics of responders and non-responders were not significantly different. Despite these limitations, our study had several strengths. This is the first study conducted among elderly rural population of Nepal to explore all traditional risk factors of CVD including biochemical assessment. We used trained enumerators to acquire data related to the participants at their own home. We performed the oral glucose tolerance test to confirm diabetes along with the fasting blood sugar. Therefore, findings could be cautiously generalized to other population.

\section{Conclusions}

Cardiovascular risk factors and their clustering were common in the rural population of Nepal. Almost all of the participants displayed on risk factor, with the majority of the participants presenting with one or clusters of two-three risk factors. When different risk factors aggregate together, their effect would be multiplicative to develop cardiovascular diseases. Therefore, comprehensive intervention to address multiple risk factors should be immediately planned and implemented to reduce the risk factors and future burden of cardiovascular diseases in a rural population of Nepal.

\footnotetext{
Abbreviations

BMI: Body mass index; CVD: Cardiovascular diseases; DBP: Diastolic blood pressure; HDL: High-density lipoprotein; LDL: Low-density lipoprotein; METs: Metabolic equivalents of task; NCD: Non-communicable diseases; SBP: Systolic blood pressure; STEPs: Stepwise approach to surveillance
}

\section{Acknowledgements}

This paper is based on the thesis submitted to Bangladesh Institute of Health Sciences (BIHS) as a partial fulfillment of M.Phil degree in Noncommunicable Diseases under the University of Dhaka. The authors want to express their sincere gratitude and appreciation to Mr. Matthew Bourke, PhD student, Victoria University, Australia for copy editing of the manuscript. We really appreciate Prof. Liaquet Ali, Director of Bangladesh Institute of Health Science (BIHS) for his kind support and motivation during M.Phil and thesis period. We would thank Mr. Ramchandra Adhikari, Managing Director of Karmada Hospital Pt.Lt. for providing laboratory, logistics, managerial, and transportation facilities. We would like to appreciate and thank Laboratory Technician Mr. Bikash Siluwal for withdrawing and analyzing blood samples We would like to thank Mr. Shailendra Pandit, Miss Pratiksha Adhikari, Miss Yem Kumari Gurung, Dr. Anil Koju, Dr. Krishna Malakar, Mr. Dwarika Mishra, Janaklal Shreshtha, and secretaries of Bhowtewodar and Sundarbazar VDC who played the key role in community mobilization, data collection, and data management. Finally, we would like to acknowledge the study team and study participants.

\section{Funding}

This research work (M.Phil thesis) was funded by the 'Norad's Programme for Master Studies (NOMA)' grant of the University of Oslo, Norway. The funding body did not have any role in the study design and collection, analysis, and interpretation of data and in writing the manuscript.

\section{Availability of data and materials}

The datasets used and/or analyzed during the current study available from the corresponding author on reasonable request.

\section{Authors' contributions}

MKK conceptualized the main thesis, trained data collectors, curated the data, performed formal analysis, interpreted the result, wrote the original draft, and finalized it; MSAMA supervised the quality of the main thesis, critically reviewed, and edited the manuscript; MZ investigated the project, involved in data curation, interpreted the results, and critically reviewed the manuscript; PCB and PB involved in project administration, acquisition, compilation, analysis, and interpretation of data, reviewed and edited the orginal draft; RD involed in project administration and investigation, analysed the result, reviewed the draft and provided intellectual comments on the manuscript; SD and AS allocated the resources, oversaw the acquisition of data, revised the main thesis, and the manuscript critically. All authors read and approved the final manuscript.

\section{Ethics approval and consent to participate}

Ethical Review Committee of Nepal Health Research Council reviewed and approved the study. Enumerators informed about study objectives, data collection procedures, benefits and risks of the study, confidentiality, and anticipated use of the results to all eligible participants. Then, the trained enumerators (health professionals) obtained written consent or thumb impression (if unable to write) using a consent form in Nepali language.

\section{Competing interests}

The authors declare that they have no competing interests.

\section{Publisher's Note}

Springer Nature remains neutral with regard to jurisdictional claims in published maps and institutional affiliations.

\section{Author details \\ 'Bangladesh Institute of Health Sciences (BIHS), Dhaka, Bangladesh. ${ }^{2}$ Department of Community Medicine, Bangladesh Institute of Health Sciences (BIHS), Dhaka, Bangladesh. ${ }^{3}$ Padmakanya Campus, Tribhuvan University (TU), Kathmandu, Nepal. ${ }^{4}$ Institute of Medicine (IOM), Tribhuvan University, Kathmandu, Nepal. ${ }^{5}$ Ministry of Health and Population (MoHP), Kathmandu, Nepal. ${ }^{6}$ College of Health and Biomedicine, Victoria University, Melbourne, Australia.}

Received: 27 September 2017 Accepted: 24 May 2018 Published online: 31 May 2018

\section{References}

1. Cardiovascular Diseases (CVDs) Fact Sheet; 2017. Available at [http://www. who.int/en/news-room/fact-sheets/detail/cardiovascular-diseases-(cvds)]. Accessed 14 Aug 2017.

2. WHO. Global Atlas on Cardiovascular Disease Prev Control. Geneva: WHO; 2011

3. Bhandari G, Angdembe M, Dhimal M, Neupane S, Bhusal C. State of noncommunicable diseases in Nepal. BMC Public Health. 2014;14(1):23.

4. Pyakurel P, Karki P, Lamsal M, Ghimire A, Pokharel PK. Cardiovascular risk factors among industrial workers: a cross-sectional study from eastern Nepal. J Occup Med Toxicol. 2016;11:25.

5. Yusuf S, Hawken S, Ounpuu S, Dans T, Avezum A, Lanas F, McQueen M, Budaj A, Pais P, Varigos J, et al. Effect of potentially modifiable risk factors associated with myocardial infarction in 52 countries (the INTERHEART study): case-control study. Lancet. 2004;364(9438):937-52.

6. WHO. Glob Health risks: Mortality and burden of disease attributable to selected major risks. Geneva: World Health Organization; 2009. 
7. Aryal KK, Mehata S, Neupane S, Vaidya A, Dhimal M, Dhakal P, Rana S, Bhusal CL, Lohani GR, Paulin FH, et al. The burden and determinants of non communicable diseases risk factors in Nepal: findings from a Nationwide STEPS survey. PLoS One. 2015;10(8):e0134834.

8. Neupane D, Shrestha A, Mishra SR, Bloch J, Christensen B, McLachlan CS, Karki A, Kallestrup P. Awareness, prevalence, treatment, and control of hypertension in western Nepal. Am J Hypertens. 2017;30(9):907-13.

9. Karmacharya BM, Koju RP, LoGerfo JP, Chan KC, Mokdad AH, Shrestha A, Sotoodehnia N, Fitzpatrick AL. Awareness, treatment and control of hypertension in Nepal: findings from the Dhulikhel heart study. Heart Asia. 2017;9(1):1-8.

10. Dhungana RR, Pandey AR, Bista B, Joshi S, Devkota S. Prevalence and associated factors of hypertension: a community-based cross-sectional study in municipalities of Kathmandu, Nepal. Int J Hypertens. 2016;2016:1656938.

11. Khanal MK, Dhungana RR, Bhandari P, Gurung Y, Paudel KN. Prevalence, associated factors, awareness, treatment, and control of hypertension: findings from a cross sectional study conducted as a part of a community based intervention trial in Surkhet, mid-western region of Nepal. PLoS One. 2017;12(10):e0185806.

12. Gyawali B, Sharma R, Neupane D, Mishra SR, van Teijlingen E, Kallestrup P. Prevalence of type 2 diabetes in Nepal: a systematic review and metaanalysis from 2000 to 2014. Glob Health Action. 2015;8:29088.

13. D'Agostino RB Sr, Vasan RS, Pencina MJ, Wolf PA, Cobain M, Massaro JM, Kannel WB. General cardiovascular risk profile for use in primary care: the Framingham heart study. Circulation. 2008;117(6):743-53.

14. WHO. Prevention of Cardiovascular Diseases: Pocket guidelines for assessment and management of cardiovascular risk. Geneva: World Health Organization; 2007

15. Gao $B$, Zhang $L$, Wang $H$. Clustering of major cardiovascular risk factors and the association with unhealthy lifestyles in the Chinese adult population. PLoS One. 2013;8(6):e66780.

16. Unal B, Critchley JA, Capewell S. Explaining the decline in coronary heart disease mortality in England and Wales between 1981 and 2000. Circulation. 2004;109(9):1101-7.

17. Puska P. From Framingham to North Karelia: from descriptive epidemiology to public health action. Prog Cardiovasc Dis. 2010;53(1):15-20.

18. Yan R, Li W, Yin L, Wang Y, Bo J. Cardiovascular diseases and risk-factor burden in urban and rural communities in high-, middle-, and low-income regions of China: a large community-based epidemiological study. J Am Heart Assoc. 2017;6(2)

19. Zhao Y, Yan H, Yang R, Li Q, Dang S, Liu R, Pei L, Cao L, Marshall RJ, Wang D. Status of cardiovascular health among adults in a rural area of Northwest China: results from a cross-sectional study. Medicine. 2016;95(28):e4245.

20. Khanal MK, Ahmed MSAM, Moniruzzaman M, Banik PC, Dhungana RR, Bhandari $P$, Devkota S, Shayami A. Total cardiovascular risk for next 10 years among rural population of Nepal using WHO/ISH risk prediction chart. BMC Res Notes. 2017;10:120

21. CBS. National Population and Housing Census 2011, vol. 05. 1st ed. Kathmandu: Central Bureau of Statistics; 2014.

22. WHO. WHO STEPS Surveillance Manual: The WHO STEPwise approach to chronic disease risk factor surveillance / Noncommunicable Diseases and Mental Health. Geneva: World Health Organization; 2005.

23. Poverty in Nepal 2010-11, NLSS-III, 2010-11; 2017. Available at [ http://cbs. gov.np/nada/index.php/catalog/37 ]. Accessed 14 Aug 2017.

24. Alcohol and Heart Health, AHA recommendation; 2017. Available at [http://www. heart.org/HEARTORG/HealthyLiving/HealthyEating/Nutrition/Alcohol-and-HeartHealth_UCM_305173_Article.jsp\#.WWhfzBWGPIU]. Accessed 10 Aug 2017.

25. WHO. Preventing and Managing the Global Epidemic of Obesity. Report of the World Health Organization Consultation of Obesity. Geneva: WHO; 1997.

26. WHO. Waist circumference and waist-hip ratio: report of a $\mathrm{WHO}$ expert consultation. Geneva: WHO; 2008.

27. Chobanian AV, Bakris GL, Black HR, Cushman WC, Green LA, Izzo JL Jr, Jones DW, Materson BJ, Oparil S, Wright JT Jr, et al. The Seventh Report of the Joint National Committee on Prevention, Detection, Evaluation, and Treatment of High Blood Pressure: the JNC 7 report. JAMA. 2003:289(19):2560-72.

28. WHO. Definition and diagnosis of diabetes mellitus and intermediate hyperglycemia: report of a WHO/IDF consultation. Geneva: World Health Organization; 2006

29. Third Report of the National Cholesterol Education Program (NCEP) expert panel on detection, evaluation, and treatment of high blood cholesterol in adults (adult treatment panel III) final report. Circulation. 2002;106(25):3143-421. https://www.ncbi.nlm.nih.gov/pubmed/12485966.
30. WHO. Age standardization of rates: A new WHO standard. Genava: World Health Organization; 2001

31. Dhungana RR, Devkota S, Khanal MK, Gurung Y, Giri RK, Parajuli RK, Adhikari A, Joshi S, Hada B, Shayami A. Prevalence of cardiovascular health risk behaviors in a remote rural community of Sindhuli district, Nepal. BMC Cardiovasc Disord. 2014;14:92.

32. Dhungana RR, Khanal MK, Pandey AR, Thapa P, Devkota S, Mumu SJ, Shayami A, Ali L. Assessment of short term cardiovascular risk among 40 years and above population in a selected Community of Kathmandu, Nepal. J Nepal Health Res Counc. 2015;13(29):66-72.

33. Thapa N, Aryal KK, Puri R, Shrestha S, Shrestha S, Thapa P, Mehata S, Thapa $P$, Banjara MR, Stray-Pedersen B. Alcohol consumption practices among married women of reproductive age in Nepal: a population based household survey. PLoS One. 2016;11(4):e0152535.

34. Vaidya A, Oli N, Aryal U, Karki D, Krettek A. Disparties in fruit and vegetable intake by socio-demographic characteristics in peri-urban Nepalese adults: findings from the heart-health associated research and dissemination in the community (HARDIC) study, Bhaktapur, Nepal. Journal of Kathmandu Medical College. 2014:2(1):9.

35. Rose D, Richards R. Food store access and household fruit and vegetable use among participants in the US food stamp program. Public Health Nutr. 2004;7(8):1081-8.

36. Azagba S, Sharaf MF. Disparities in the frequency of fruit and vegetable consumption by socio-demographic and lifestyle characteristics in Canada. Nutr J. 2011;10(1):118.

37. Guthold R, Ono T, Strong KL, Chatterji S, Morabia A. Worldwide variability in physical inactivity a 51-country survey. Am J Prev Med. 2008;34(6):486-94.

38. Sharma SK, Ghimire A, Radhakrishnan J, Thapa L, Shrestha NR, Paudel N, Gurung K, R M, Budathoki A, Baral N et al: Prevalence of hypertension, obesity, diabetes, and metabolic syndrome in Nepal. Int J Hypertens 2011, 2011:821971.

39. Vaidya A, Krettek A. Physical activity level and its sociodemographic correlates in a peri-urban Nepalese population: a cross-sectional study from the Jhaukhel-Duwakot health demographic surveillance site. Int J Behav Nutr Phys Act. 2014;11:39.

40. Traversy G, Chaput J-P. Alcohol consumption and obesity: an update. Curr Obes Rep. 2015:4(1):122-30.

41. Mehta KD, Karki P, Lamsal M, Paudel IS, Majhi S, Das BK, Sharma S, Jha N, Baral N. Hyperglycemia, glucose intolerance, hypertension and socioeconomic position in eastern Nepal. Southeast Asian J Trop Med Public Health. 2011;42(1):197-207.

42. Chhetri MR, Chapman RS. Prevalence and determinants of diabetes among the elderly population in the Kathmandu Valley of Nepal. Nepal Med Coll J. 2009;11(1):34-8

43. Pandey AR, Karki KB, Mehata S, Aryal KK, Thapa P, Pandit A, Bista B, Dhakal P, Dhimal M. Prevalence and determinants of comorbid diabetes and hypertension in Nepal: evidence from non communicable disease risk factors STEPS survey Nepal 2013. J Nepal Health Res Counc. 2015; 13(29):20-5.

44. Aryal KNS, Mehata S, Vaidya A, Singh S, Paulin F, Madanlal RG, Riley LM, Cowan M, Guthold R, Singh SP, Bhusal CL, Lohani GR. Non communicable diseases risk factors: STEPS Survey Nepal 2013. Nepal Health Research Council. Kathmandu; 2014.

45. YR Limbu SR, Ono K, Kurokawa M, J-I Yanagida G, Rai NG, Rai CK. Lipid profile of adult Nepalese population. Nepal Med Coll J. 2008;10(1):4-7.

46. Zaman MM, Bhuiyan MR, Karim MN, Zaman M, Rahman MM, Akanda AW, Fernando T. Clustering of non-communicable diseases risk factors in Bangladeshi adults: an analysis of STEPS survey 2013. BMC Public Health. 2015;15(1):659.

47. Kaukua J, Turpeinen A, Uusitupa M, Niskanen L. Clustering of cardiovascular risk factors in type 2 diabetes mellitus: prognostic significance and tracking. Diabetes Obes Metab. 2001;3(1):17-23.

48. Murakami Y, Okamura T, Nakamura K, Miura K, Ueshima H. The clustering of cardiovascular disease risk factors and their impacts on annual medical expenditure in Japan: community-based cost analysis using gamma regression models. BMJ Open. 2013;3(3)

49. Vaidya A. Tackling cardiovascular health and disease in Nepal: epidemiology, strategies and implementation. Heart Asia. 2011;3(1):87-91.

50. Nissinen A, Berrios X, Puska P. Community-based noncommunicable disease interventions: lessons from developed countries for developing ones. Bull World Health Organ. 2001;79(10):963-70. 
51. Puska P. Community-based cardiovascular prevention programs: theory and practice. Archives of Iran Med. 2013;16(1):2-3.

52. Kar SS, Thakur JS, Jain S, Kumar R. Cardiovascular disease risk management in a primary health care setting of North India. Indian Heart J. 2008;60(1):19-25.

53. WHO. Package of essential noncommunicable (PEN) disease interventions for primary health care in low-resource settings. Geneva: WHO; 2010.

Ready to submit your research? Choose BMC and benefit from:

- fast, convenient online submission

- thorough peer review by experienced researchers in your field

- rapid publication on acceptance

- support for research data, including large and complex data types

- gold Open Access which fosters wider collaboration and increased citations

- maximum visibility for your research: over $100 \mathrm{M}$ website views per year 